(c) 2018. This manuscript version is made available under the CC-BY-NC-ND 4.0 license http:// creativecommons.org/licenses/by-nc-nd/4.0/

This is a preprint post peer review version:

Please cite as:

Akhtar, P., Khan, Z., Tarba, S., Jayawickrama, U. (2017). The Internet of Things, dynamic data and information processing capabilities and operational agility. Technological

Forecasting and Social Change. DOI: 10.1016/j.techfore.2017.04.023.

Pervaiz Akhtar ${ }^{\mathrm{a}}$, Zaheer Khan ${ }^{\mathrm{b}}$, Shlomo Tarba ${ }^{\mathrm{c}}$, Uchitha Jayawickrama ${ }^{\mathrm{d}}$

${ }^{a}$ Management Systems, Logistics Institute, Faculty of Business, Law and Politics, University of Hull

${ }^{\mathrm{b}}$ Kent Business School, University of Kent

${ }^{\mathrm{c}}$ Birmingham Business School, The University of Birmingham

${ }^{\mathrm{d}}$ School of Computing and Digital Technologies, Staffordshire University

\title{
The Internet of Things, dynamic data and information processing capabilities, and operational agility
}

\begin{abstract}
Whilst there are promising links between the Internet of Things (IoTs), dynamic data and information processing capabilities (DDIPCs), and operational agility, scholars have not conducted enough empirical studies that offer convincing evidence for the use of the IoTs and relevant linkages. This study therefore examines the links between such constructs and provides managerial implications for contemporary data and information driven managers who adopt evidence-based decision making for better operational outcomes. The results obtained from structural equation modelling indicate that the use of the IoTs is the key determinant for operational agility and also plays a vital role in establishing DDIPCs that further reinforce it. Additionally, DDIPCs mediate the relationship between the use of the IoTs and operational agility. By persuasively building these links based on theoretical arguments and testing them by using a unique dataset, this study contributes to the deeper understanding of the mechanisms by which the use of the IoTs and DDIPCs strengthen operational agility.
\end{abstract}

Keywords: Internet of Things; dynamic capabilities; dynamic data and information processing; operational agility; data and knowledge intensive services 


\section{Introduction}

The Internet of Things (IoTs) has recently emerged as a key disruptive technology that not only plays a main role in daily activities, but also affects business operations and global economic systems as a whole (Atzori et al., 2010; Wortmann and Flüchter, 2015). With the use of the IoTs (i.e., the inter-networking of devices with the ability to send and receive data), business operations are becoming more agile and connected. Also, the data and information produced through the IoTs is used to generate knowledge that is ultimately employed to monitor and control business network operations. The companies that utilize the links between the IoTs and dynamic data and information processing capabilities (DIDPCs) achieve a better competitive advantage; they do so because their daily business operations become more agile as a result of these developments in their IT infrastructures (Christopher, 2000; Heisterberg and Verma, 2014; Lou et al., 2011; No et al., 2015). The significance of the IoTs and of its linkages with operational effectiveness, data, and informed decision making has been highlighted by key IT players. For instance, Microsoft believes that "the IoTs can make a difference to your business by beginning with the things in your business that matter the most. It's really the internet of your things, and it starts by building on the infrastructure you already have in place, using familiar devices and services in new ways, and incorporating the right technology to ultimately help you use data to create insights and make more informed business decisions" (Edson, 2014). As a result of this business appeal, "the IoTs, which excludes PCs, tablets and smart-phones, will grow to 26 billion units installed in 2020, representing an almost 30-fold increase from 0.9 billion in 2009, and IoTs product and service suppliers will generate incremental revenue exceeding \$300 billion” (Gartner, 2013). Also, the Vodafone IoTs Barometer claims that $76 \%$ of businesses view the IoTs as critical for the future, $90 \%$ of organizations have already integrated IoTs data into their existing IT 
systems, and $63 \%$ of such adopters have increased their growth by at least $20 \%$ (Forbes, 2016; Vodafone, 2016).

These statistics have provided growing evidence that the use of the IoTs is demonstrably crucial in creating data and information that are associated with the capabilities of organizations, providing them with insights related to operational agility and effective decision making. The impacts of the IoTs seem to be limitless, as the connected devices provide data and information about both internal and external operations. Despite the claims and statistics presented above, the academic studies on the links between the use of the IoTs, DDIPCs, and operational agility are just emerging; the research concerning the mechanisms through which the IoTs affects operational agility is still in its infancy. More specifically, the linkages between the use of the IoTs and DIDPCs to generate knowledge suitable to improve operational agility have neither been effectively researched nor statistically estimated. Above all, the field is still devoid of clear theoretical bases (Bresciani et al., 2017; Cram and Newell, 2016; No et al., 2015; Teece, 2014a).

Given that the academic research on the use of the IoTs is just emerging, the first contribution of this study is to develop a theoretical framework by building inter-relationships between the use of the IoTs and DDIPCs, and operational agility. Conceptually, the IoTs and DDIPCs seem well linked, but answering the question of how they impact operational agility substantially contributes to closing the knowledge gap in the operational and IT domains. Secondly, operational agility itself has not been well established. In the IT literature, operational agility generally focuses on quick responses, accurate actions, and cost-efficiency pertaining to both customers and internal operations; we provide evidence that it is also linked at the macro-level. Consequently, operational agility is a second-order construct that integrates both its internal and external aspects. Finally, we test the framework and provide 
significant evidence by following a comprehensive statistical procedure and using a unique dataset.

\section{Theory and hypotheses}

\subsection{Literature and definitions}

The term "the Internet of Things" is used for those devices that have network connectivity and the ability to send or receive data and information to other connected objects. It is a major developmental wave-after the desktop and web-based ones-in the information and communication technology (ICT) sectors (Atzori et al., 2010; Ma, 2011). The idea is essentially based on the device-to-device connections and communication that can be effectively established using smart devices (e.g., wearable devices and Chromecast, Samsung, and Apple smartphones), their functionalities (e.g., Wi-Fi, Bluetooth), cloud computing facilities, and sensors. These devices provide accurate and real-time data and information that are used to track and trace operational resources and personnel. This enhances visibility, leading to the development of agile operations among connected business networks (Lu and Ramamurthy, 2011; Miorandi et al., 2012; Yang et al., 2013). Yang et al. (2013) provided evidence that the IoTs enhances the effectiveness of response operations in terms of the accountability of resources, specialized actions, assessment of situations, resource allocation, and multi-organizational coordination. Similarly, micro-sensors can be used to monitor patient health and smart meters can be used to monitor electricity consumption. Also, the transportation data and information linked with any connected devices are collected and processed for effective traffic management or traffic supply chain visibility and agility (Elhenawy and Rakha, 2017; Uden and He, 2017; White et al., 2005).

An organization's dynamic capabilities are viewed as its ability to promptly adopt changes and process data and information for actionable knowledge or analytics that enable the effective tackling of changes in the market (No et al., 2015; Ramírez et al., 2013; Teece, 
2014a). Such capabilities help organizations to quickly turn structured and unstructured data into insights and knowledge that can be used to improve business operations. An example of such capabilities includes the complex text mining ability used to respond to consumer feedback or reviews and thus improve customer service (Kim et al., 2012; No et al., 2015). Organizations equipped with advanced electronic devices capture real-time contextual data and information that are frequently used in their daily supply chain operations. They also utilize individual speech recognition capabilities to speed up their warehouse operations. These dynamic capabilities are not only imperative for contemporary data-driven business operations, but also help to improve business network visibility and operational agility (Chou et al., 2007; Dweekat et al., 2017; Hazen et al., 2014; Reaidy et al., 2015).

In the information management literature, the term "agility" generally consists of three dimensions: operational, partnering, and customers. "Operational agility" focuses on quick responses, accurate actions, and cost-efficiency (i.e., cost economy). Importantly, it is not only related to internal processes, but also covers external operational processes. It is basically defined as the ability of organizations to swiftly react to changes and uncertainties. Secondly, "partnering" is the ability of organizations to leverage their network partners' knowledge and capabilities to assist in identifying problems and capturing opportunities to improve their performance. Finally, “customer" aspects emphasize learning from customers and acting accordingly (Huang et al., 2014; Izza et al., 2008; Sambamurthy et al., 2003). In other fields, such as supply chains and logistics (Tse et al., 2016), agility includes demand responses, customer responses, and joint planning. Huang et al. (2000) believed that agility can be used in many functions of networked enterprises, such as recovery, collaboration, partnerships, and logistics. Vickery et al. (2010) defined agility as a tool that improves responsiveness to customer needs. 
In addition to its characteristics described above (quick, accurate, and cost-efficient), operational agility assists in adjusting operational changes and provides more flexibility in day-to-day operations (Langer and Alting, 2000; Pawson and Wade, 2003). It also enables the swift redesigning and building of new processes, ultimately enabling the exploitation of market opportunities that are part of external business environments (Seebach et al., 2011; Tallon and Pinsonneault, 2011). It is evident from the literature that there is no single definition of agility or operational agility, and that the latter mainly involves: 1) speed, 2) accuracy, 3) cost-efficiency, and 4) flexibility. Importantly, it encompasses both internal and external aspects in regard to the characteristics mentioned above. Correspondingly, we define operational agility as the ability of organizations to cope with demands and changes by considering the four aspects listed above both internally and externally. Thus, our definition of operational agility consists of two dimensions - internal and external operational agilitywhich are measured in terms of 1) speed, 2) accuracy, 3) cost-efficiency, and 4) flexibility.

\subsection{Hypotheses}

\subsubsection{Use of the IoTs and operational agility}

Due to its business benefits, the IoTs is regarded as one of the important digital revolutions of the modern age (Atzori et al., 2010; Del Giudice \& Straub, 2011). It can act as an important storage and communication hub that links and transfers information between connected organizations and their networks (Liu et al., 2013; Uckelmann et al., 2011). Due to these characteristics, IoTs devices play a vital role in enabling modern day businesses to build better connectivity and progressive operations to improve their agility (Atzori et al., 2010; Del Giudice and Straub, 2011). The knowledge that comes through such connected devices offers agility, scalability, and reliability in the form of the timely processing of information for better decision making (Atzori et al., 2010; Del Giudice and Straub, 2011; Uckelmann et al., 2011). 
The information collected through the IoTs enhances the productivity of business processes. In other words, the knowledge and analytical insights gathered through this connectivity enable business networks to make informed and evidence-based decisions, and play a vital role in building dynamic data and information processing capabilities (Grant, 1996; Teece, 2007, 2014a; Uden and He, 2017). Ultimately, such capabilities improve internal and external operational agility (Heisterberg and Verma, 2014), which has nowadays emerged as one of the key capabilities IT-oriented businesses need to survive and prosper (Braunscheidel and Suresh, 2009; Bresciani et al., 2017; Heisterberg and Verma, 2014). In a sense, the use of the IoTs is the key determinant that transforms the nature and ways of doing business, as it is noted that investing in IT infrastructure capabilities can be vital to develop organizational agility (Mathiassen and Pries-Heje, 2006; Weill et al., 2002). Through the use of the internet and digital-oriented technologies, companies are transferring vital and timely information to their international and global network partners, enabling the latter to act quickly on that information and become more agile (Lou et al., 2011). It has been suggested that the IoTs played an important role in facilitating communication, particularly the exchange of data and knowledge between entities. Such IT devices are vital for the improvement of both internal and external operational agility (Guillemin and Friess, 2009; Yang et al., 2013).

The use of the IoTs has the potential to generate both depth and breadth of knowledge, which is basically used to enhance operational agility (Atzori et al., 2010; Del Giudice and Straub, 2011; Uden and He, 2017). The research suggests that IoTs-technology has a great potential for business operations such as manufacturing, distribution, transportation, and allocation of resources (Atzori et al., 2010; Wortmann and Flüchter, 2015). It is further believed that the IoTs can revolutionize the way in which companies gather data. It can also transform business processes and the management of knowledge in ways that could play an 
important role in operational agility of network partners (Atzori et al., 2010; Xu et al., 2016). Due to the vital role it plays, it can be argued that the use of the IoTs is one of the key dynamic capabilities of modern businesses (Elhenawy and Rakha, 2017; Teece, 2007, 2014a; Uden and He, 2017). Researchers (e.g., Kim et al., 2012; Liu et al., 2013; Miorandi et al., 2012; Yang et al., 2013) expressed their belief that the use of such an advanced IT infrastructure enables organizations to integrate, build, and reconfigure both their internal and external operations - which can become more agile - attaining data and analytics-driven leadership in constantly shifting business environments (Akhtar et al., 2016). In fact, the use of the IoTs provides agility to all business network operations and the implementation of such advanced technology is critical for contemporary business operations to become agile (Forbes, 2016; Gubbi et al., 2013; Yang et al., 2013). The use of the IoTs essentially enhances operational agility due to the fine-grained knowledge that comes through the devices connected with the internet and the ability of companies to receive and process information in a timely fashion (Forbes, 2016; Gubbi et al., 2013; Uden and He, 2017; Yang et al., 2013). It is suggested that companies can detect the physical status of things through sensors and internet-enabled technologies, which enables not only the collection and processing of detailed data, but also immediate responses to any changes taking place in the real world, thus helping in the enhancement of operational agility (Hwang et al., 2013; Lee and Lee, 2015; Uckelmann et al., 2011). Based on these arguments, we propose the following hypothesis:

Hypothesis 1: The use of the IoTs is positively related to the enhancement of operational agility.

\subsubsection{The use of the IoTs and dynamic data and information processing capabilities}

Besides making operations agile, the use of the IoTs provides large amounts of structured and unstructured data, which can enhance an organization's dynamic data and information 
processing capabilities for knowledge generation (Del Giudice and Straub, 2011; Gubbi et al., 2013; Malhotra, 2000, 2005). Dynamic data and information processing capabilities can be valuable resources for network partners (Teece, 2007; Zahra and George, 2002), and are also vital for the development of a competitive advantage in high volatile markets (Teece et al., 1997). Organizations need dynamic data and information processing capabilities to process the huge volume of data coming through various connected devices with diverse digital technologies (Atzori et al., 2010; Barnaghi et al., 2013; Del Giudice and Straub, 2011; Elhenawy and Rakha, 2017).

The IoTs may also impact an organization's dynamic data and information processing capabilities due to the dynamic nature of the knowledge that comes through it (Uden and He, 2017; Waller and Fawcett, 2013; Xiang et al., 2015). One of the key benefits of the IoTs is the enormous amount of data generated from devices connected to the internet. An organization's ability to process such a vast amount of data determines the overall usefulness of the IoTs. Put differently, those organizations that invest in data and information processing capabilities will be in a better position to exploit the data coming through the IoTs (Gubbi et al., 2013). In a sense, the use of the IoTs puts additional pressure on organizations to improve their internal data and information processing capabilities in order to take advantage in a timely fashion of the huge amount of data and information generated through the devices connected with the internet, and thus develop a sustainable competitive advantage. It is also suggested that the use of the IoTs requires organizations not only to equip themselves with massive data storage capabilities, but also to develop the ability to process data in a timely and speedy manner in order to make real-time decisions (Lee \& Lee, 2015), thus indicating the important influence exerted by the use of the IoTs on dynamic data and information processing capabilities. In order to benefit from the use of the IoTs, many organizations are now developing dynamic data and information processing, and collaboration capabilities to 
share real-time information with both their customers and supply networks (Bradley et al., 2013; Lee and Lee, 2015). The development of such capabilities is vital in view of the massive amounts of heterogeneous data that are generated by the devices connected with the IoTs and that organizations need to process and store efficiently. According to a Gartner report, the current architectures of organizations' data processing centres are not suited to deal with the vast amount of heterogeneous data, a capability that may be crucial to enhance agility (Rivera and van der Meulen, 2014).

Modern organizations invest in advanced IT infrastructures (e.g., the IoTs and big data technologies) to improve their dynamic data and information processing capabilities in order to take advantage of the knowledge they provide (Gubbi et al., 2013; Malhotra, 2000; Uden and He, 2017; Wortmann and Flüchter, 2015). Such technologies then help the effective transfer of valuable insights to network partners, with the aim of improving the overall network agility (Gubbi et al., 2013; Lou et al., 2011; Uckelmann et al., 2011). Since the IoTs is connected through network-oriented systems interlinked with various smart objects that produce and consume vital information, IoTs-devices play an important role in enhancing dynamic data and information processing capabilities (Heisterberg and Verma, 2014; Miorandi et al., 2012; Weill et al., 2002).

The information that comes through such smart objects can play an important role for an organization's wide data and information processing capabilities in terms of the generation of important and timely knowledge (Atzori et al., 2010; Miorandi et al., 2012). It has also been noted that devices connected with various objects generate huge amount of data that can influence the development of dynamic data and information processing capabilities (Atzori et al., 2010; O'Leary, 2013). In order to effectively utilize and process the information obtained through the IoTs, organizations need to possess dynamic data and information processing capabilities (Saldanha et al., 2015). The possession of such capabilities is important for 
digitally connected organizations as they handle huge amounts of data, and their timely processing can affect the whole network (Chen and Zhang, 2014). Thus, the sensing, seizing, and transferring of opportunities and capabilities can be developed through the IoTs, and organizations can reconfigure their key processes and capabilities to handle agile operations based on the data and information processing capabilities linked with the IoTs (Kim et al., 2012; Liu et al., 2013; Miorandi et al., 2012; Uden and He, 2017; Yang et al., 2013). These IoTs-enabled capabilities need to be linked with analytical insights used to improve business operations (Xu et al., 2016). The above discussion leads us to the following hypothesis:

Hypothesis 2: The use of the IoTs is positively related to the enhancement of dynamic data and information processing capabilities.

\subsubsection{Dynamic data and information processing capabilities and operational agility}

Dynamic data and information processing capabilities (DDIPCs) play an important role in achieving operational agility (Heisterberg and Verma, 2014; Perera et al., 2014; Weill et al., 2002). This is one of the core capabilities needed to process and generate knowledge from the huge amount of data coming through the IoTs (Uden and He, 2017). Such capabilities for knowledge generation turn raw data into explicit and useful information that network partners can use to develop their operational agility (Uden and He, 2017; Wixom et al., 2013). Without such capabilities, organizations would be unable to compete effectively and develop the competitive advantages linked to being agile and first in accessing markets (Heisterberg and Verma, 2014; Wixom et al., 2013).

The data coming from the IoTs need to be processed to generate valuable insights; those organizations that do not have the dynamic data and information processing capabilities to generate knowledge and develop and enhance their operational agility are often at a competitive disadvantage compared to those that do. The possession of dynamic data and information processing capabilities to generate knowledge not only enables the collection of 
valuable data but also helps to store important datasets that can provide marketing actionable insights utilized for operational agility (Uden \& He, 2017; Weill et al., 2002; Woerner and Wixom, 2015). Studies also point out that information processing related infrastructures are vital to enhance agility in complicated business operations (Liu et al., 2013; Weill et al., 2002). Such capabilities for dynamic data and information processing are the higher order capabilities needed to develop agility (Heisterberg and Verma, 2014; Teece, 2014b; Zahra and George, 2002), which consists of multiple dimensions (Seebach et al., 2011; Tallon and Pinsonneault, 2011). This discussion leads us to propose that:

Hypothesis 3: DDIPCs are positively related to operational agility.

\subsubsection{The mediating role played by DDIPCs}

If DDIPCs mediate the relationships between the IoTs and operational agility, the three correlations need to be verified between:

1) The use of the IoTs and operational agility (hypothesis 1)

2) The use of the IoTs and DDIPCs (hypothesis 2)

3) DDIPCs and operational agility (hypothesis 3)

Finally, the first correlation (hypothesis 1) should become insignificant when the three correlations (1, 2, and 3) are verified and the construct (DDIPCs) is controlled (Baron and Kenny, 1986; Preacher and \& Hayes, 2008; Sobel, 1982). For each condition, this study develops one hypothesis, each of which is based on the literature that is discussed in Section 2. Fig. 1 presents a graphic version of these hypothesized conditions and their interrelationships.

Additionally, the use of the IoTs alone may not aid organizations in developing their operational agility, as they would also require in-house capabilities suited to process the vast amount of data and information in a timely manner. Thus, there may be other central mechanisms and underlying processes that, together with the IoTs, can enhance operational 
agility (Bresciani et al., 2017; Helmsen et al., 2012). One such underlying process and mechanism could be the possession of dynamic data and information processing capabilities suited to enhance the multiple dimensions of internal and external agility and contribute to overall performance. This points at the need for effective in-house dynamic data and information processing capabilities that would enable organizations to take advantage of the huge volume of data processing and information sharing, and would play a central role (i.e., a mediating role) in strengthening the links between the IoTs and operational agility (Bresciani et al., 2017; Chen et al., 2014; Marinagi et al., 2015)..

Although the value of general IT capabilities has been highlighted by practitioners and scholars alike, the knowledge obtained from and the central role played by data and information processing have not been explored. As it is an emerging and complex domain interconnected with many operational dimensions, any mediating roles played in the link between the use of the IoTs and agility therefore remain the subject of debate in the interdisciplinary IT-business literature (Bresciani et al., 2017; Chen et al., 2014; Marinagi et al., 2015; Matthias et al., 2017). This gap and discussion thus lead us to propose the following hypothesis.

Hypothesis 4: The link between the use of the IoTs and operational agility is mediated by DDIPCs.
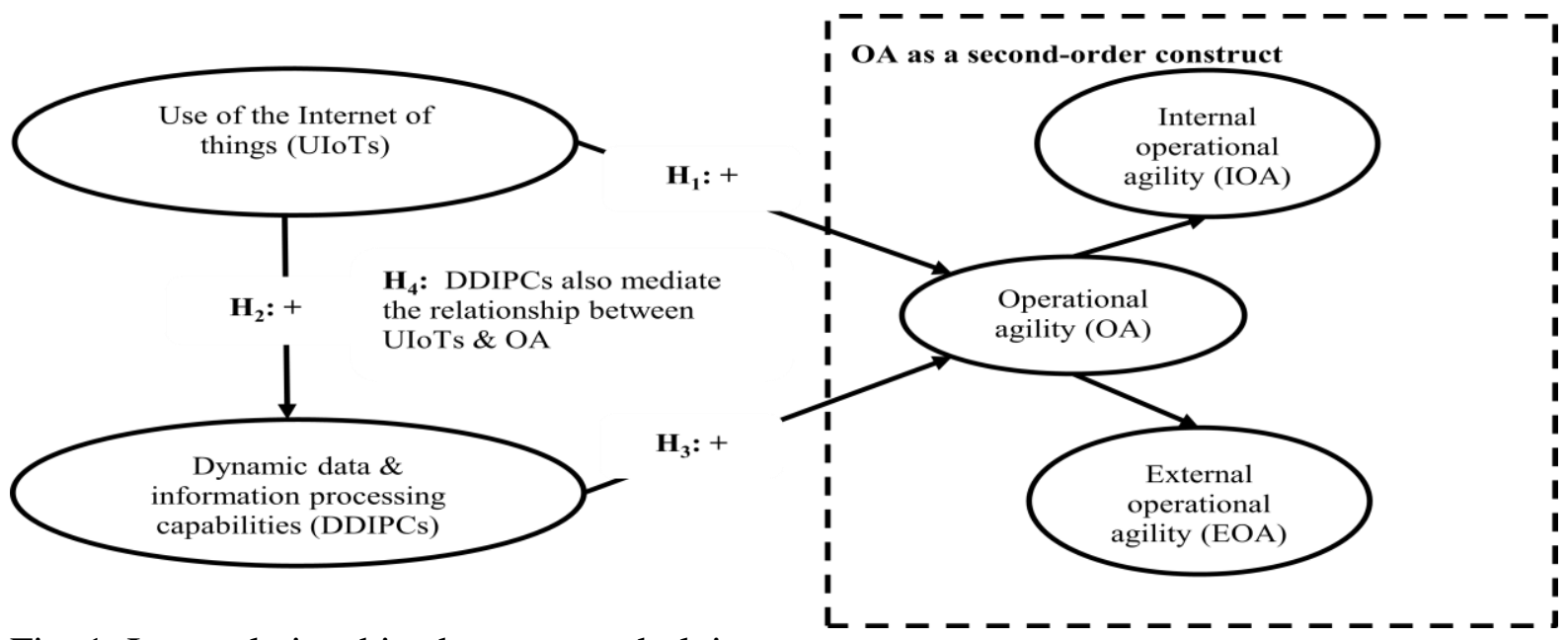

Fig. 1. Inter-relationships between underlying constructs 


\section{Methods}

\section{1 questionnaire development, operationalization and respondents}

To operationalize the key constructs, we undertook a thorough literature review. This helped to identify the scales used in past studies. The questionnaire items were then reviewed and pilot-tested to ensure content validity. A seven-point scale was used to measure the extent to which the respondents agreed or disagreed $(1=$ strongly disagree and $7=$ strongly agree). Endogeneity biases (Abdallah et al., 2015; Antonakis et al., 2010; Qin, 2015)—such as common-method variance (CMV), measurement error, omitted variables and simultaneous bias—were also addressed (Antonakis et al., 2010; Hamilton and Nickerson, 2003). To deal with common-method variance, the guidelines provided by Tourangeau et al. (2000) and Podsakoff et al. (2003) were also utilized (avoiding unfamiliar words, double-barrelled questions, and technical terms). Additionally, Harman's one-factor test provided multiple factors, which explained greater variance compared to a single factor solution or combinations, and assisted to investigate the CMV. Further, the marker variable technique (the variable being the number of languages known by the respondents) proposed by Lindell and Whitney (2001) and the latent factor approach did not highlight any issues (Malhotra et al., 2006). To deal with the measurement error, we used the maximum likelihood estimate and a multiple indicator approach, which corrected the biasing effects (Frone et al., 1994). To deal with omitted and simultaneous biases, well established theories were used (Antonakis et al., 2014; Antonakis and Dietz, 2011).

The KOMPASS database was utilized to identify and contact a total of 900 respondents working in the selected European IT, telecommunication, and energy companies. After excluding incomplete ones, a total of 205 useable participant responses were subjected to structural equation modelling, and the characteristics of the respondents are shown in Table 1. 
Table 1

Respondents and their characteristics.

\begin{tabular}{llrr}
\hline Categories & & Numbers & percentages \\
\hline Job titles & IT directors & 97 & 47 \\
& IT operations manager & 65 & 32 \\
& Implementation managers & 43 & 21 \\
Company & IT & 91 & 44 \\
types & Telecommunication & 62 & 30 \\
& Energy & 52 & 26 \\
Employees & $>250$ & 109 & 53 \\
& $>50 \&<250$ & 96 & 47 \\
Turnover(\$m) & $>€ 50$ million & 110 & 54 \\
& $<€ 50$ million & 95 & 46 \\
Total & & 205 & 100 \\
\hline $3.2 . M e a s u r e m$
\end{tabular}

3.2. Measurement models and quality checks

Multiple items were used to develop the measurement models. The construct, Use of the Internet of Things (UIoTs), was measured using ten items, followed by Dynamic Data and |Information Processing Capabilities (DDIPCs) assessed through eight items. The secondorder construct, Operational Agility (OA) was measured by two sub-constructs, called Internal Operational Agility and External Operational Agility, each consisting of four items. Three control variables (Respondent Types, Industry Types, and Company Sizes) were also used to ensure the quality of this study; these are given in Table 1 . Table 2 presents the constructs, items, reliability measures, average variance explained, and loadings. These statistics provide acceptable psychometric properties of our scales. Additionally, we found that there was no non-response bias in our sample. Discriminant validity was measured by using two methods. First, the correlation between the constructs did not exceed 0.85, and ranged between 0.27 and 0.57 (Kline, 2011) as listed in Table 3. Second, the square of the correlation $\left(\phi^{2}\right)$ between each pair of constructs was less than the average variance explained (AVE) (Chiang et al., 2012; Sekaran, 2000). The descriptive statistics and correlation matrix of the constructs are shown in Table 4. 
Table 2

Measurement models and reliability statistics.

Constructs, items' brief description, sources and reliability measures $\quad \lambda$

Use of Internet of Things, UIoTs (Kim et al., 2012; Liu et al., 2013; Miorandi et al., 2012;

Yang et al., 2013) [Cronbach's $\alpha=0.95 ; \mathrm{AVE}=0.66 ; \mathrm{CR}=0.94$ ]

UIoTs provides us real-time solutions (UIoTs1) 0.73

UIoTs wirelessly provides us comprehensive data about the surroundings (UIoTs2) $\quad 0.78$

We are highly depend on IoTs in order to track and trace our objects (UIoTs3) 0.72

We use IoTs to monitor our operational environments (UIoTs4)

We frequently get data through IoTs-devices (UIoTs5) 0.76

Our IoTs technology effectively identifies the required objects (UIoTs6) 0.94

UIoTs continuously assists to innovate our business operations (UIoTs7) 0.94

Integrating advanced IoTs is the main part of our business strategy (UIoTs8) 0.88

UIoTs improves the connectivity of networks (UIoTs9, deleted due to low loadings) -----

$\begin{array}{ll}\text { We often collect unstructured data via IoTs (UIoTs10) } & 0.75\end{array}$

Dynamic data and information processing capabilities, DDIPCs (Chou et al., 2007; Hazen

et al., 2014; Kim et al., 2012) [Cronbach's $\alpha=0.93$; AVE $=0.61$; $\mathrm{CR}=0.93$ ]

We have excellent expertise to process structural data (DDIPCs1) 0.93

Our analytics personnel (i.e., team) actively get insights from unstructured data

(DDIPCs2) 0.71

The programming skills of our personnel greatly helps us to get analytical insights $\quad 0.77$

from the large datasets produced from smart-devices we use regularly (DDIPCs3)

Our personnel effectively get insights from web-based data (DDIPCs4) 0.66

We effectively process complicated data \& information (DDIPCs5) 0.89

We effectively use real-time information for day-to-day operations (DDIPCs6) 0.82

Our IT infrastructure strongly focuses on information integration by using advanced $\quad 0.69$

technology (DDIPCs7)

We frequently disseminate useful information across our departments (DDIPCs8) $\quad 0.73$

Operational agility, OA (Agarwal et al., 2006; Sambamurthy et al., 2003; Seebach et al., 2011; Tallon and Pinsonneault, 2011) [Cronbach's $\alpha=0.72 ; \mathrm{AVE}=0.67 ; \mathrm{CR}=0.80$ ]

Internal operational agility, IOA [Cronbach's $\alpha=0.90 ; \mathrm{AVE}=0.67 ; \mathrm{CR}=0.89] \quad 0.87$

Reliability of our offerings [i.e., services and products] has increased (IOA1) 0.81

Our day-to-day operations are flexible for customized demand (IOA2) 0.77

Our offerings are more cost-efficient than competitors (IOA3) 0.84

We accomplish greater speed in delivering our offerings (IOA4) 0.86

External operational agility, EOA [Cronbach's $\alpha=0.93 ; \mathrm{AVE}=0.76 ; \mathrm{CR}=0.93] \quad 0.76$

Our response to market changes is very reliable (EOA1) 0.94

We have greater flexibility in our offerings to adopt market changes (EOA2) 0.83

We efficiently redesign our offerings to adopt market changes (EOA3) 0.95

$\begin{array}{lr}\text { We are very quick to adopt market opportunities (EOA4) } & 0.74\end{array}$

Cronbach's alpha, $\alpha=$ items reliability; $\lambda=$ loadings; AVA =average variance explained; C.R $=$ construct reliability 
Table 3

Discriminant validity.

\begin{tabular}{llll|l}
\hline & Statistics & & Condition met \\
\hline Constructs & $\phi$ & $\phi^{2}$ & AVE & $\phi^{2}<$ AVE \\
\hline UIoTs \& DDIPCs & 0.40 & $0.16^{\mathrm{a}}$ & $0.64^{\mathrm{b}}$ & Yes \\
UIoTs \& IOA & 0.29 & 0.08 & 0.67 & Yes \\
UIoTs \& EOA & 0.32 & 0.10 & 0.71 & Yes \\
DDIPCs \& IOA & 0.34 & 0.12 & 0.64 & Yes \\
DDIPCs \& EOA & 0.27 & 0.07 & 0.69 & Yes \\
IOA \& EOA & 0.57 & 0.32 & 0.72 & Yes \\
\hline
\end{tabular}

$\phi=$ correlation between factors, ${ }^{\mathrm{a}} \phi^{2}, 0.40 * 0.40=0.16 ;{ }^{\mathrm{b}} \mathrm{AVE},(0.66+0.61) / 2=0.64$ (UIoTs $\&$ DDIPCs)

Table 4

Descriptive statistics and correlation matrix.

\begin{tabular}{llllllll}
\hline Constructs & $\bar{x}$ & $\sigma$ & UIoTs & DDIPCs & $\begin{array}{l}\text { IO } \\
\text { A }\end{array}$ & EOA & OA \\
\hline UIoTs & 6.16 & 0.37 & 1 & & & & \\
DDIPCs & 6.27 & 0.39 & 0.40 & 1 & & & \\
IOA & 6.29 & 0.45 & 0.29 & 0.34 & 1 & & \\
EOA & 6.33 & 0.51 & 0.32 & 0.27 & 0.5 & 1 & \\
OA & 6.31 & 0.42 & 0.35 & 0.34 & 0.8 & .90 & 1 \\
\hline
\end{tabular}

$\overline{\bar{x}}$ (mean); $\sigma$ (standard deviation); all correlations are significant at $p<0.01$

\subsection{Establishing a second-order construct for structural results}

It was imperative to establish a second-order construct (i.e., OA) before running for the structural model. Fig. 2a shows the first order construct, which provides acceptable measures to establish a second-order one, and the fit indices listed underneath Fig. 2a also support the data. The second-order construct, its loadings, $R^{2}$ values, and relevant fit indices are depicted in Fig. 2b. 


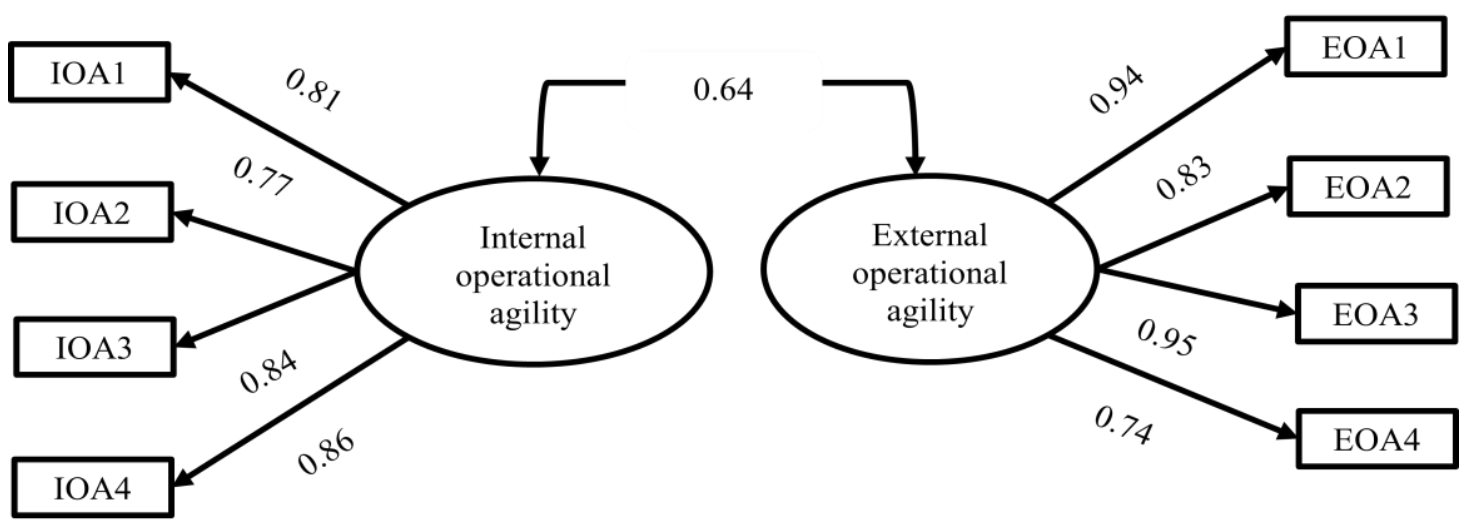

All loadings were significant at $\mathrm{p}<0.01 ; \chi^{2} / \mathrm{df}=1.962 ; \mathrm{CFI}=0.988 ; \mathrm{TLI}=0.980 ; \mathrm{IFI}=$ $0.988 ;$ RMSEA $=0.069$

Fig. 2a. First-order constructs for operational agility.

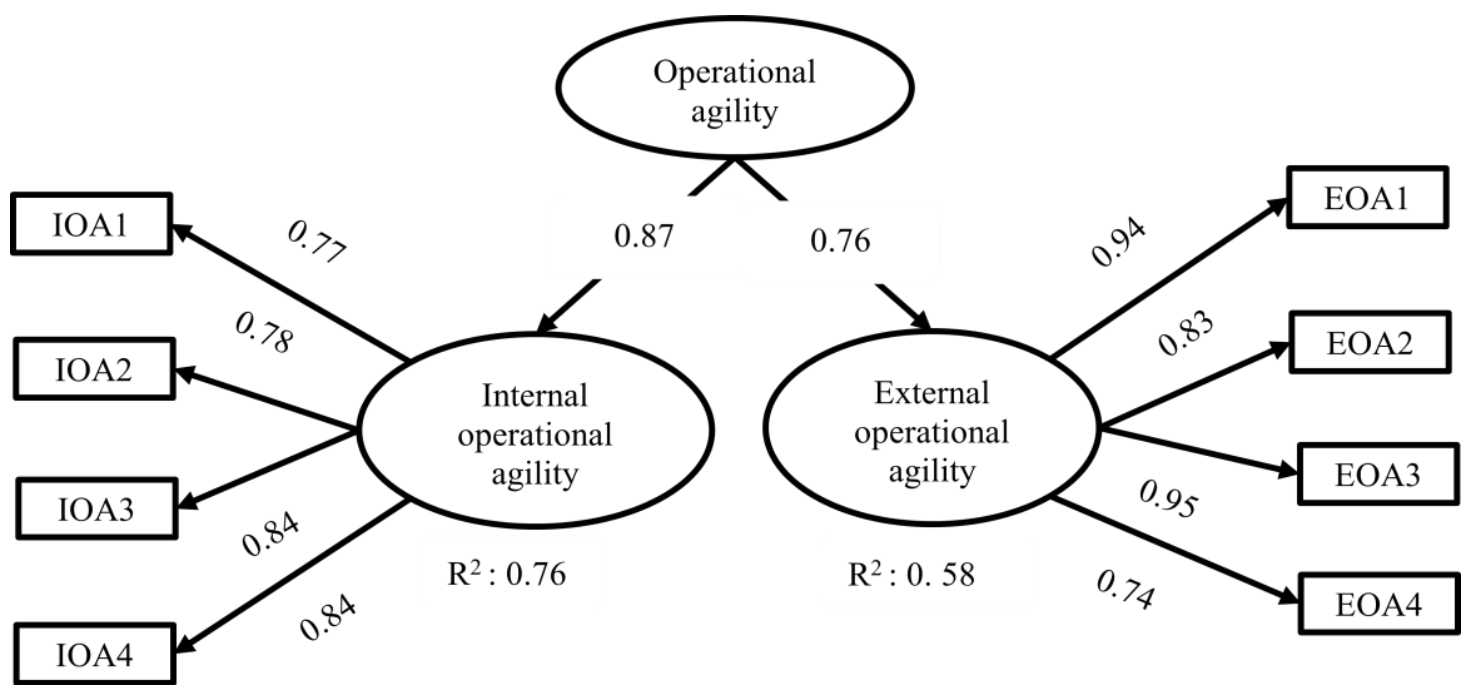

All loadings were significant at $\mathrm{p}<0.01 ; \chi^{2} / \mathrm{df}=1.838 ; \mathrm{CFI}=0.990 ; \mathrm{TLI}=0.983 ; \mathrm{IFI}=$ $0.990 ;$ RMSEA $=0.064$

Fig. 2b. Operational agility as a second-order construct.

\section{Hypotheses and results}

Fig. 3 presents the results against proposed hypotheses, $R^{2}$ values, and fit indices. Hypothesis 1 proposes that the use of IoTs is positively related to operational agility. This hypothesis is supported at $p<0.01$ with $\beta=0.29$. Hypothesis 2 (the use of IoTs is positively associated with dynamic data and information processing capabilities, DDIPCs) and hypothesis 3 (DDIPCs positively links with operational agility) are also supported with $\beta=$ 
$0.38(p<0.01)$ and $\beta=0.26(p<0.01)$ respectively. Additionally, the fit indices strongly support the model and the $R^{2}$ values, which ranged from $14 \%$ to $40 \%$, are given below in Fig. 2, showing stronger support to the final model.

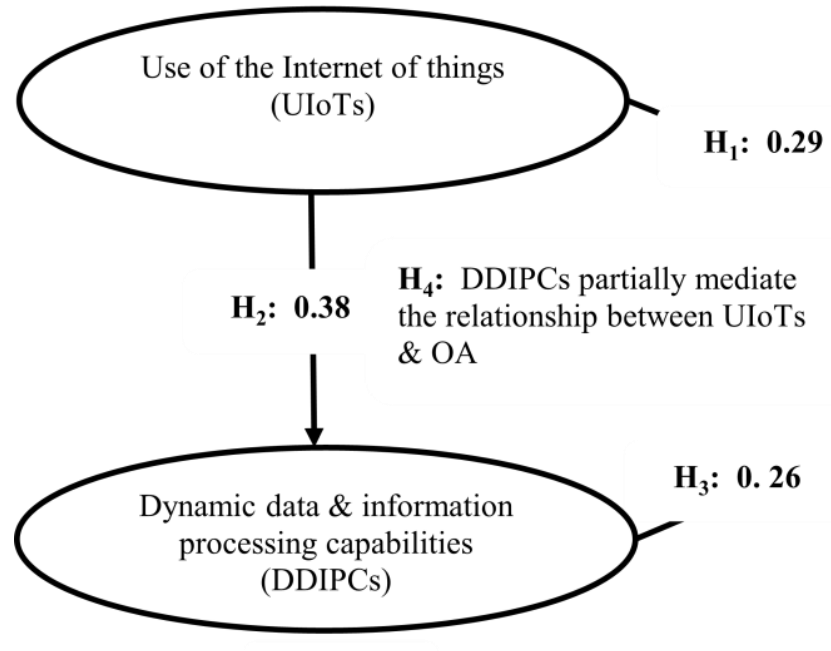

$\mathrm{R}^{2}: 0.14$

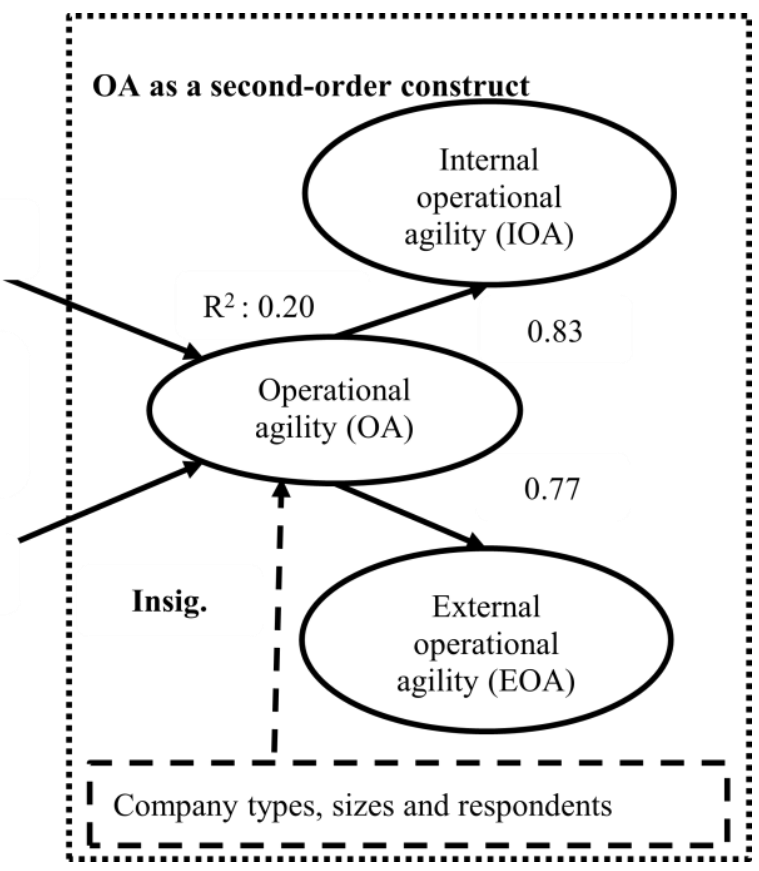

All loadings were positively significant at $\mathrm{p}<0.01 ; \chi^{2} / \mathrm{df}=1.181 ; \mathrm{CFI}=0.990 ; \mathrm{TLI}=0.987 ; \mathrm{IFI}=$ $0.990 ;$ RMSEA $=0.032$

Fig. 3. Structural results for hypotheses, $R^{2}$ values and fit indices.

$\mathrm{H}_{4}$ [mediating analysis, DDIPCs mediate the relationship between the use of IoTs and operational agility] was tested by utilizing three approaches; a) the causal-steps approach (Baron \& Kenny, 1986), b) Sobel typed-tests (Sobel, 1982), and c) Bootstrapping (Preacher and Hayes, 2008). The causal-steps approach showed that the independent variable (UIoTs) significantly affects the dependent one (Operational Agility, OA) with $\beta=0.35$ and $\mathrm{t}$-value $=$ 5.24 at $p<0.001$. The independent variable also significantly affects the mediating one (DDIPCS), as $\beta=0.41$ and $\mathrm{t}$-value $=6.35$ at $p<0.001$. Further, DDIPCS (mediator) significantly affects $\mathrm{OA}$ with $\beta=0.34$ and $\mathrm{t}$-value $=5.13$ at $p<0.001$. Finally, when the model was controlled for DDIPCS, the previous relationship (i.e., between UIoTs and OA) was reduced $(\beta=0.25$ and $\mathrm{t}$-value $=3.53$ at $p<0.001)$, the results thus yielded a partial, 
rather than a full mediation as the relationship was still significant. The Sobel test also depicted that the indirect effect of the independent variable on the dependent one via the mediator is significantly different from zero at $p<0.001$. Additionally, the Aroian and Goodman tests provided similar results.

The bootstrapping method with 5,000 samples and a 95\% confidence interval was also used (Preacher and Hayes, 2008). First, it was found that the use of IoTs was positively associated with $\operatorname{ES}[(\beta=0.40, \mathrm{t}=5.24, p<0.001)]$ total effects. It was also found that the use of IoTs was positively associated with DDIPCs $[(\beta=0.42, \mathrm{t}=6.35, p<0.001)]$, and the mediator (DDIPCs) was positively associated with OA $[(\beta=0.26, \mathrm{t}=3.38, p<0.001)]$. Additionally, the results showed that the direct effect of the use of IoTs on OA was reduced $[(\beta=0.28, \mathrm{t}=3.53, p<0.001)]$ when controlled for DDIPCs, thus, it was partially mediated, with a confidence level between 0.036 and 0.21 .

\section{Discussion and conclusions}

\subsection{Summary of findings}

The aim of this research is to understand the role played by the Internet of Things (IoTs) and its links with dynamic data and information processing capabilities (DDIPCs) and operational agility, which are two of the key factors involved in dealing with dynamic and competitive environments (Yang et al., 2013). The IoTs has emerged as one of the main technologies of the modern era, with companies from various industrial settings utilizing connected devices with various sensors and data processing technologies to glean useful data to develop competitive advantages (Atzori et al., 2010; Wortmann and Flüchter, 2015). Despite the IoTs' potential, the research in this area is in its infancy and the field lacks a clear understanding of the particular mechanisms and underlying processes through which the IoTs can develop and enhance organizational operational agility. Such technologies are enabling organizations to utilize both structured and unstructured data and information coming through 
the IoTs, creating valuable knowledge that can be utilized to develop and enhance business operations and improve both operational agility and manufacturing scalability (Christopher, 2000; Heisterberg and Verma, 2014; Lou et al., 2011; No et al., 2015).

Based on the responses obtained from 205 top managers from various European knowledge intensive and IT-oriented industries (IT, Telecommunications, and Energy companies), we find support for the four hypotheses. The findings indicate that the use of the IoTs (Hypothesis 1) is indeed vital for the development and enhancement of organizational operational agility (Atzori et al., 2010; Del Giudice and Straub, 2011; Miorandi et al., 2012; Uden and He, 2017; Yang et al., 2013). Those companies that rely more on the IoTs are in a better position to improve their operational agility compared to those that are lagging behind in such aspect. The IoTs enhances the former's network connectivity and makes their business more agile and responsive to the changing business requirements of the 21 st century. This finding is interesting as existing studies and media reports point out that IoTs-devices are important for the accumulation of important data and information (Uden and He, 2017); yet, there is a very limited empirical support for claims of how the generation and accumulation of valuable knowledge from the large volume of data can be utilized to improve operational agility (Bresciani et al., 2017; Chen et al., 2014; Marinagi et al., 2015; Matthias et al., 2017). Thus, our findings provide an important piece of evidence to support claims that the IoTs is imperative for operational agility.

Our findings also support our second hypothesis, which states that the use of the IoTs is important for the development and enhancement of DDIPCs. Generic dynamic capabilities have been widely studied in the strategic management literature and other related fields. However, little research has investigated modern DDIPCs linked with the use of the IoTs (Kim et al., 2012; Liu et al., 2013; Miorandi et al., 2012; Uden and He, 2017; Xu et al., 2016; Yang et al., 2013), which can effectively be used for both internal and external dimensions of 
agility. The data produced by the IoTs are utilized for actionable insights that may be helpful to enhance operational agility. The IoTs does not only enable the collection of valuable data but also assists in producing real-time information useful for operational agility. These IoTsenabled capabilities are vital to building DDIPCs (Wang et al., 2017; Xu et al., 2016).

The findings further indicate that DDIPCs play a key enabler role for the development and enhancement of organizational operational agility. Dynamic capabilities are suggested to be the key in developing a competitive advantage, and also aid in competing in highly changeable and turbulent business environments. Thus, those organizations that invest in their dynamic data and information processing capabilities can find themselves in better positions to take advantage of data and information to enhance their operational agility (Agarwal et al., 2006; Sambamurthy et al., 2003; Seebach et al., 2011; Tallon and Pinsonneault, 2011; Xu et al., 2016). The use of the IoTs alone may not provide full benefits. In this paper, we have also argued that those organizations that make timely investments in the development of their dynamic data and information processing capabilities will be in a better position to effectively and efficiently utilize the vast amount of data made available by the use of the IoTs. Thus, we advance a novel perspective by proposing important mechanisms, linked with DDIPCs, that may explain the differential effect of the IoTs on the enhancement of operational agility. The findings support the proposed mediating effect of DDIPCs on the link between the use of the IoTs and operational agility. By proposing and testing this novel mediating effect, the results provide important insights into the underlying mechanisms through which the use of the IoTs can affect operational agility via the mediating role of DDIPCs, which, so far, had not been theorized and tested in the existing studies on this topic, as such advanced capabilities are still emerging (e.g., big data analytics and unstructured data) (Bresciani et al., 2017; Chen et al., 2014; Marinagi et al., 2015; Matthias et al., 2017; Xu et al., 2016). 


\subsection{Contributions and implications}

This study contributes to the existing debate on the usefulness of the IoTs in four important ways. First, it contributes theoretically by advancing arguments based on traditional dynamic capability perspectives (e.g., Teece, 2007; Teece et al., 1997) and modern dynamic capability requirements (e.g., Mikalef and Pateli, 2017; Wang et al., 2017; Xu et al., 2016; Yang et al., 2013), proposing a framework that utilizes various literature streams such as the IoTs, a dynamic capability-based view and agility to advance the understanding of the important relationships that exist between the use of IoTs, dynamic data and information processing capabilities, and operational agility (Atzori et al., 2010; Xu et al., 2016). So far, the research on IoTs and its impacts had not been established on sound underlying theoretical bases (Atzori et al., 2010; Wang et al., 2017; Xu et al., 2016; Yang et al., 2013), therefore, the contribution of our empirical findings to these aspects substantially closes such research gap.

Second, we advance the understanding of operational agility; the existing studies had narrowly focussed on operational agility and its dimensions. We extended the traditional operational agility concept with multiple dimensions linked with internal and external operational agility rooted in the micro and macro environments (e.g., Sambamurthy et al., 2003) of the operational sides of modern businesses. Third, the article contributes to the dynamic capabilities literature by proposing and testing the influence of DDIPCs on operational agility. This is an important contribution because, although the existing studies had highlighted the important role played by traditional dynamic capabilities, there was hitherto limited empirical support for how modern data and IT-driven capabilities affect operational agility (Kim et al., 2012; Tan et al., 2015; Wang et al., 2017; Xu et al., 2016). Finally, the article provides important insights into the underlying mechanisms through which the IoTs impact operational agility by proposing a mediation effect of DDIPC, which 
provides an important basis for future studies (Bresciani et al., 2017; Chen et al., 2014; Marinagi et al., 2015; Matthias et al., 2017).

The findings of this article have important implications for practitioners. First, they highlight the important role played by the IoTs for operational agility, thus indicating the need for managers to invest in such disruptive technologies and improve the IT organizational infrastructure of their companies in order to take advantage of vast amount of data and information coming through the devices connected to the internet in order to develop both operational agility and manufacturing scalability. The era of the IoTs may significantly change the IT-industry, as it facilitates real-time data and information sharing for operational purposes. Second, the article points toward the importance of having DDIPCs in order to utilize the data and information coming through the IoTs for the generation of vital knowledge. Thus, companies may benefit by improving their internal DDIPCs and recruiting relevant employees equipped with data and information-driven skills. The use of the IoTs alone may not be enough to get the maximum operational benefits; organizations often need in-house human capabilities for data processing and information sharing. These capabilities, together with the IoTs, may provide managers with better opportunities to get greater operational benefits. Managers with such capabilities may take advantage of large datasets, which can unpack actionable insights for operational benefits-such as improving customer service, product quality, speed, product reliability, and supply chain visibility. In fact, effective DDIPCs can play a central role in bridging the gap between the IoTs and operational benefits. The value of general human-IT capabilities has been highlighted by practitioners. However, general business managers may not be fully aware of the valuable knowledge generated by modern DDIPCs, as it is an emerging domain and mainly remains the subject of IT departments. Contemporary business operations are inundated with structured and unstructured data and modern businesses rely on new tools and techniques to 
process data and share information; this challenges traditionally minded managers to equip themselves with these tools to achieve better operational outcomes. Continuous learning can help such managers to tackle those challenges. Lastly, investing in DDIPCs and systematically improving IT-related capabilities is important for the development and enhancement of operational dimensions, which is a key message that managers should take on board.

\subsection{Limitations and future research}

Despite the important contributions, this article has several limitations that offer important opportunities for future research. First, it utilizes information collected from three Europeanbased key knowledge intensive and IT-oriented industries (IT, Telecommunications, and Energy). Future studies need to test the proposed framework in other industrial and geographical contexts by comparing less IT-oriented industries with highly IT dependent ones. This could also be performed by comparing developed and emerging economies. Second, there could potentially be other variables that can influence organizational operational agility, such as the skills needed to deal with the IoTs/data and information processing, and internal cultural barriers to such modern implementations. Third, future studies could build on this one and examine other potential mediating and moderating variables. Fourth, there is the need to utilize social network techniques and understand how network partners improve their operational agility by being widely connected through various digital technologies and internet devices and how knowledge-related resources flow through such networks and impact their members' agility. Lastly, future studies need to combine qualitative case studies and large scale surveys to disentangle the impact of the IoTs and of dynamic data and information processing capabilities on operational agility. A potential contribution would be made by case studies based on the large unstructured datasets that are produced by the IoTs. 


\section{References}

Abdallah, W., Goergen, M., O'Sullivan, N., 2015. Endogeneity: How Failure to Correct for it can Cause Wrong Inferences and Some Remedies. British Journal of Management 26, 791-804.

Agarwal, A., Shankar, R., Tiwari, M., 2006. Modeling the metrics of lean, agile and leagile supply chain: An ANP-based approach. European Journal of Operational Research 173, 211-225.

Akhtar, Tse, M., Khan, Z., Rao-Nicholson, R., 2016. Data-driven and adaptive leadership contributing to sustainability of global agri-food supply chains connected with emerging markets. International Journal of Production Economics.

Antonakis, J., Bendahan, S., Jacquart, P., Lalive, R., 2010. On making causal claims: A review and recommendations. The Leadership Quarterly 21, 1086-1120.

Antonakis, J., Bendahan, S., Lalive, R., 2014. Causality and endogeneity: Problems and solutions, The Oxford handbook of leadership and organizations.

Antonakis, J., Dietz, J., 2011. More on testing for validity instead of looking for it. Personality and Individual Differences 50, 418-421.

Atzori, L., Iera, A., Morabito, G., 2010. The internet of things: A survey. Computer networks 54, 2787-2805.

Barnaghi, P., Sheth, A., Henson, C., 2013. From Data to Actionable Knowledge: Big Data Challenges in the Web of Things [Guest Editors' Introduction]. IEEE Intelligent Systems 28, 6-11.

Baron, R.M., Kenny, D.A., 1986. The moderator-mediator variable distinction in social psychological research: Conceptual, strategic, and statistical considerations. Journal of personality and social psychology 51, 1173-1182.

Bradley, J., Barbier, J., Handler, D., 2013. Embracing the Internet of everything to capture your share of \$14.4 trillion. White Paper, Cisco.

Braunscheidel, M.J., Suresh, N.C., 2009. The organizational antecedents of a firm's supply chain agility for risk mitigation and response. Journal of Operations Management 27, 119140.

Bresciani, S., Ferraris, A., Del Giudice, M., 2017. The management of organizational ambidexterity through alliances in a new context of analysis: Internet of Things (IoT) smart city projects. Technological Forecasting and Social Change.

Chen, C.P., Zhang, C.-Y., 2014. Data-intensive applications, challenges, techniques and technologies: A survey on Big Data. Information Sciences 275, 314-347.

Chen, Y., Wang, Y., Nevo, S., Jin, J., Wang, L., Chow, W.S., 2014. IT capability and organizational performance: the roles of business process agility and environmental factors. European Journal of Information Systems 23, 326-342.

Chiang, C.-Y., Kocabasoglu-Hillmer, C., Suresh, N., 2012. An empirical investigation of the impact of strategic sourcing and flexibility on firm's supply chain agility. International Journal of Operations \& Production Management 32, 49-78.

Chou, T.-C., Chang, P.-L., Cheng, Y.-P., Tsai, C.-T., 2007. A path model linking organizational knowledge attributes, information processing capabilities, and perceived usability. Information \& management 44, 408-417.

Christopher, M., 2000. The agile supply chain: competing in volatile markets. Industrial Marketing Management 29, 37-44.

Cram, W.A., Newell, S., 2016. Mindful revolution or mindless trend? Examining agile development as a management fashion. European Journal of Information Systems 25, 154-169. 
Del Giudice, M., Straub, D., 2011. IT and entrepreneurism: an on-again, off-again love affair or a marriage? MIS Quarterly 35, 3-11.

Dweekat, A.J., Hwang, G., Park, J., 2017. A supply chain performance measurement approach using the internet of things: toward more practical SCPMS. Industrial Management \& Data Systems 117.

Edson, B., 2014. Creating the internet of your things. Microsoft Corporation.

Elhenawy, M., Rakha, H.A., 2017. Random Forest-Hidden Markov Transportation Mode Recognition Model Using Smartphone Sensor Data.

Forbes, 2016. Vodafone IoT Barometer: 76\% Of Businesses Say Internet of Things Will Be Critical to Future Success, Available at:

http://www.forbes.com/sites/louiscolumbus/2016/07/14/vodafone-iot-barometer-76-ofbusinesses-say-internet-of-things-will-be-critical-to-future-success/\#4ae6c5b544de (retrieved 09 Oct. 2016).

Frone, M.R., Russell, M., Cooper, M.L., 1994. Relationship between job and family satisfaction: Causal or noncausal covariation? Journal of Management 20, 565-579.

Gartner, J., 2013. Gartner Says the Internet of Things Installed Base Will Grow to 26 Billion Units By 2020.

Grant, R.M., 1996. Toward a knowledge-based theory of the firm. Strategic Management Journal 17, 109-122.

Gubbi, J., Buyya, R., Marusic, S., Palaniswami, M., 2013. Internet of Things (IoT): A vision, architectural elements, and future directions. Future Generation Computer Systems 29, 1645-1660.

Guillemin, P., Friess, P., 2009. Internet of things strategic research roadmap, The Cluster of European Research Projects, Tech. Rep. European Commission Information Society and Media dia

Hamilton, B.H., Nickerson, J.A., 2003. Correcting for endogeneity in strategic management research. Strategic organization 1, 51-78.

Hazen, B.T., Boone, C.A., Ezell, J.D., Jones-Farmer, L.A., 2014. Data quality for data science, predictive analytics, and big data in supply chain management: An introduction to the problem and suggestions for research and applications. International Journal of Production Economics 154, 72-80.

Heisterberg, R., Verma, A., 2014. Creating business agility. Hoboken: Wiley.

Helmsen, J., Koglin, U., Petermann, F., 2012. Emotion regulation and aggressive behavior in preschoolers: The mediating role of social information processing. Child Psychiatry \& Human Development 43, 87-101.

Huang, Ceroni, J., Nof, S., 2000. Agility of networked enterprises-parallelism, error recovery and conflict resolution. Computers in Industry 42, 275-287.

Huang, Pan, S.L., Ouyang, T.H., 2014. Developing information processing capability for operational agility: implications from a Chinese manufacturer. European Journal of Information Systems 23, 462-480.

Hwang, K., Dongarra, J., Fox, G.C., 2013. Distributed and cloud computing: from parallel processing to the internet of things. Morgan Kaufmann.

Izza, S., Imache, R., Vincent, L., Lounis, Y., 2008. An approach for the evaluation of the agility in the context of enterprise interoperability, Enterprise Interoperability III. Springer, pp. 3-14.

Kim, G., Shin, B., Kwon, O., 2012. Investigating the value of sociomaterialism in conceptualizing IT capability of a firm. Journal of Management Information Systems 29, 327-362.

Kline, R.B., 2011. Principles and practice of structural equation modeling. Guilford press. 
Langer, G., Alting, L., 2000. An architecture for agile shop floor control systems. Journal of Manufacturing Systems 19, 267.

Lee, I., Lee, K., 2015. The Internet of Things (IoT): Applications, investments, and challenges for enterprises. Business Horizons 58, 431-440.

Lindell, M.K., Whitney, D.J., 2001. Accounting for common method variance in crosssectional research designs. Journal of applied psychology 86, 114-121.

Liu, H., Ke, W., Wei, K.K., Hua, Z., 2013. The impact of IT capabilities on firm performance: The mediating roles of absorptive capacity and supply chain agility. Decision Support Systems 54, 1452-1462.

Lou, P., Liu, Q., Zhou, Z., Wang, H., 2011. Agile supply chain management over the internet of things, Management and Service Science (MASS), 2011 International Conference on. IEEE, pp. 1-4.

Lu, Y., Ramamurthy, K., 2011. Understanding the link between information technology capability and organizational agility: An empirical examination. MIS Quarterly, 931-954.

Ma, H.-D., 2011. Internet of things: Objectives and scientific challenges. Journal of Computer science and Technology 26, 919-924.

Malhotra, N.K., Kim, S.S., Patil, A., 2006. Common method variance in IS research: A comparison of alternative approaches and a reanalysis of past research. Management Science 52, 1865-1883.

Malhotra, Y., 2000. Knowledge management for e-business performance: advancing information strategy to "internet time". Information Strategy: The Executive's Journal 16, 5-16.

Malhotra, Y., 2005. Integrating knowledge management technologies in organizational business processes: getting real time enterprises to deliver real business performance. Journal of knowledge management 9, 7-28.

Marinagi, C., Trivellas, P., Reklitis, P., 2015. Information quality and supply chain performance: The mediating role of information sharing. Procedia-Social and Behavioral Sciences 175, 473-479.

Mathiassen, L., Pries-Heje, J., 2006. Business agility and diffusion of information technology. European Journal of Information Systems 15, 116.

Matthias, O., Matthias, O., Fouweather, I., Fouweather, I., Gregory, I., Gregory, I., Vernon, A., Vernon, A., 2017. Making sense of Big Data-can it transform operations management? International Journal of Operations \& Production Management 37, 37-55.

Mikalef, P., Pateli, A., 2017. Information technology-enabled dynamic capabilities and their indirect effect on competitive performance: Findings from PLS-SEM and fsQCA. Journal of Business Research 70, 1-16.

Miorandi, D., Sicari, S., De Pellegrini, F., Chlamtac, I., 2012. Internet of things: Vision, applications and research challenges. Ad Hoc Networks 10, 1497-1516.

No, H.J., An, Y., Park, Y., 2015. A structured approach to explore knowledge flows through technology-based business methods by integrating patent citation analysis and text mining. Technological Forecasting and Social Change 97, 181-192.

O'Leary, D.E., 2013. Big data, the internet of things and the internet of signs. Intelligent Systems in Accounting, Finance and Management 20, 53-65.

Pawson, R., Wade, V., 2003. Agile development using naked objects, International Conference on Extreme Programming and Agile Processes in Software Engineering. Springer, pp. 97-103.

Perera, C., Zaslavsky, A., Christen, P., Georgakopoulos, D., 2014. Sensing as a service model for smart cities supported by internet of things. Transactions on Emerging Telecommunications Technologies 25, 81-93. 
Podsakoff, P.M., MacKenzie, S.B., Lee, J.-Y., Podsakoff, N.P., 2003. Common method biases in behavioral research: a critical review of the literature and recommended remedies. Journal of applied psychology 88, 879-903.

Preacher, K.J., Hayes, A.F., 2008. Asymptotic and resampling strategies for assessing and comparing indirect effects in multiple mediator models. Behavior research methods 40 , 879-891.

Qin, D., 2015. Time to Demystify Endogeneity Bias. SOAS Department of Economics Working Paper.

Ramírez, R., Österman, R., Grönquist, D., 2013. Scenarios and early warnings as dynamic capabilities to frame managerial attention. Technological Forecasting and Social Change 80, 825-838.

Reaidy, P.J., Gunasekaran, A., Spalanzani, A., 2015. Bottom-up approach based on internet of things for order fulfillment in a collaborative warehousing environment. International Journal of Production Economics 159, 29-40.

Rivera, J., van der Meulen, R., 2014. Gartner says the Internet of Things will transform the Data Center. Retrieved August 5, 2014.

Saldanha, T., Mithas, S., Krishnan, M.S., 2015. Leveraging customer involvement for fueling innovation: The role of relational and analytical information processing capabilities. Forthcoming in MIS Quarterly.

Sambamurthy, V., Bharadwaj, A., Grover, V., 2003. Shaping agility through digital options: Reconceptualizing the role of information technology in contemporary firms. MIS Quarterly, 237-263.

Seebach, C., Pahlke, I., Beck, R., 2011. Tracking the digital footprints of customers: How firms can improve their sensing abilities to achieve business agility.

Sekaran, U., 2000. Research methods for business: A skill-building approach. John Wiley \& Sons.

Sobel, 1982. Asymptotic confidence intervals for indirect effects in structural equation models, in: Leinhardt, I.S. (Ed.), Sociological Methodology 1982, San Francisco, pp. 290312.

Tallon, P.P., Pinsonneault, A., 2011. Competing perspectives on the link between strategic information technology alignment and organizational agility: insights from a mediation model. MIS Quarterly 35, 463-486.

Tan, K.H., Zhan, Y., Ji, G., Ye, F., Chang, C., 2015. Harvesting big data to enhance supply chain innovation capabilities: An analytic infrastructure based on deduction graph. International Journal of Production Economics 165, 223-233.

Teece, D.J., 2007. Explicating dynamic capabilities: the nature and microfoundations of (sustainable) enterprise performance. Strategic Management Journal 28, 1319-1350.

Teece, D.J., 2014a. A dynamic capabilities-based entrepreneurial theory of the multinational enterprise. Journal of International Business Studies 45, 8-37.

Teece, D.J., 2014b. The foundations of enterprise performance: Dynamic and ordinary capabilities in an (economic) theory of firms. The Academy of Management Perspectives 28, 328-352.

Teece, D.J., Pisano, G., Shuen, A., 1997. Dynamic capabilities and strategic management. Strategic Management Journal 18, 509-533.

Tourangeau, R., Rips, L.J., Rasinski, K., 2000. The psychology of survey response. Cambridge University Press.

Tse, Y.K., Zhang, M., Akhtar, P., MacBryde, J., 2016. Embracing supply chain agility: an investigation in the electronics industry. Supply Chain Management: An International Journal 21, 140-156. 
Uckelmann, D., Harrison, M., Michahelles, F., 2011. An architectural approach towards the future internet of things, Architecting the internet of things. Springer, pp. 1-24.

Uden, L., He, W., 2017. How the Internet of Things can help knowledge management: a case study from the automotive domain. Journal of knowledge management 21.

Vickery, S., Droge, C., Setia, P., Sambamurthy, V., 2010. Supply chain information technologies and organisational initiatives: complementary versus independent effects on agility and firm performance. International Journal of Production Research 48, 70257042.

Vodafone, 2016. Unlock the value of the Internet of Things with the 2016 Vodafone IoT Barometer, Available at: http://www.vodafone.com/business/iot/the-iot-barometer-2016 (retrieved 09 Oct. 2016).

Waller, M.A., Fawcett, S.E., 2013. Data science, predictive analytics, and big data: a revolution that will transform supply chain design and management. Journal of Business Logistics 34, 77-84.

Wang, J., Qiu, M., Guo, B., 2017. Enabling real-time information service on telehealth system over cloud-based big data platform. Journal of Systems Architecture 72, 69-79.

Weill, P., Subramani, M., Broadbent, M., 2002. Building IT infrastructure for strategic agility. MIT Sloan Management Review 44, 57-65.

White, A., Daniel, E.M., Mohdzain, M., 2005. The role of emergent information technologies and systems in enabling supply chain agility. International journal of information management 25, 396-410.

Wixom, B.H., Yen, B., Relich, M., 2013. Maximizing Value from Business Analytics. MIS Quarterly Executive 12, 111-123.

Woerner, S., Wixom, B.H., 2015. Big data: extending the business strategy toolbox. Journal of Information Technology 30, 60-62.

Wortmann, F., Flüchter, K., 2015. Internet of things. Business \& Information Systems Engineering 57, 221-224.

Xiang, Z., Schwartz, Z., Gerdes, J.H., Uysal, M., 2015. What can big data and text analytics tell us about hotel guest experience and satisfaction? International Journal of Hospitality Management 44, 120-130.

Xu, Z., Frankwick, G.L., Ramirez, E., 2016. Effects of Big Data analytics and traditional marketing analytics on new product success: A knowledge fusion perspective. Journal of Business Research 69, 1562-1566.

Yang, L., Yang, S.-H., Plotnick, L., 2013. How the internet of things technology enhances emergency response operations. Technological Forecasting and Social Change 80, 18541867.

Zahra, S.A., George, G., 2002. Absorptive capacity: A review, reconceptualization, and extension. Academy of Management Review 27, 185-203. 
Pervaiz Akhtar is a Senior Lecturer (Associate Professor), Program Leader of Logistics \& SCM, and Program Director of MSc Analytics/Data Science Division at University of Hull Business School, UK. His research has appeared in leading journals such as British Journal of Management, International Journal of Production Economics, Supply Chain Management: An International Journal, Technological Forecasting and Social Change, R\&D Management, International Journal of Human Resource Management, among others. His professional interests are mainly in network analysis, big data analytics, the IoTs, ICT, optimization, simulation, ANP applications, innovation and innovative research methods. Pervaiz has also worked for (or with) non-profit and for-profit organizations (UNICEF, JCCP, Oxfam, MSF, Islamic Relief, Red Cross, high government officials, dairy industry, FMCG companies like Unilever and Reckitt Benckiser) at senior levels (operations/logistics/project director and manager). He is the corresponding author and can be reached at pervaiz.akhtar@hull.ac.uk.

Zaheer Khan is a Reader (Associate Professor) at Kent Business School, the University of Kent. His research interests are international knowledge transfer, capability development, automotive industry, and cross-border alliances. He has published in the Journal of International Business Studies, Global Strategy Journal, International Business Review, International Marketing Review, and Industrial Marketing Management, among others. Prior to entering academia, he worked as a consultant for Capgemini Ernst \& Young, USA. He can be contacted at Z.Khan-53@kent.ac.uk.

Shlomo Y. Tarba is a Reader (Associate Professor) in Business Strategy and Head of Department of Strategy \& International Business at the Business School, University of Birmingham, UK, and a Visiting Professor in Recanati Business School, Tel-Aviv University, Israel. He received his $\mathrm{PhD}$ in Strategic Management from Ben-Gurion University and Master's in Biotechnology degree at the Hebrew University of Jerusalem, Israel.

His research interests include resilience, strategic agility, organizational ambidexterity and innovation, and mergers and acquisitions. Dr. Tarba is a member of the editorial board of Human Resource Management (US, Wiley), Journal of Management Studies, British Journal of Management, and Journal of World Business. He has serves/served as a guesteditor for the special issues at Journal of Organizational Behavior (US, Wiley), Human 
Resource Management (US, Wiley), and Management International Review. His research papers are published/forthcoming in journals such as Journal of Management (SAGE), Academy of Management Perspectives, California Management Review, British Journal of Management, Journal of World Business, Human Resource Management, Management International Review, International Business Review, International Journal of Human Resource Management, Human Resource Management Review, International Studies of Management \& Organization, Thunderbird International Business Review, and others. One of his paper has been selected and published in Best Paper Proceedings of the Academy of Management (USA) in 2006.

Dr. Tarba's recent two co-authored books are A Comprehensive Guide to Mergers \& Acquisitions: Managing the Critical Success Factors Across Every Stage of the M\&A Process by Pearson \& Financial Times Press (2014), and Mergers, Acquisitions, and Strategic Alliances: Understanding The Process by Palgrave Macmillan (2011). His consulting experience includes biotechnological and telecom companies, as well as industry association such as The Israeli Rubber and Plastic Industry Association, and The US - Israel Chamber of Commerce. He can be contacted at s.tarba@bham.ac.uk

Uchitha Jayawickrama has his first degree in Information Systems, followed by an MBA and then a PhD in Information Systems and Knowledge Management specialising in the field of Enterprise Resource Planning (ERP) systems. Uchitha has published his research in various renowned conferences, books and journals, and has won best paper awards in several international conferences. He is a reviewer for several journals and international conferences. He has editorial experience in various journals. Uchitha also has undergraduate and postgraduate teaching and curriculum design experience in both the UK and abroad. Prior to his career in academia, he worked as Oracle Applications Consultant in implementing Oracle E-Business Suite (Oracle ERP) for various industry sectors, followed by the post of Manager - IBM Solutions. He can be contacted at uchitha.jayawickrama@staffs.ac.uk 